\title{
The role of Notch ligand, Delta-like ligand 4 (DLL4), in cancer angiogenesis - implications for therapy
}

\author{
Marlena Brzozowa-Zasada (D)
}

Received: 10 March 2021 / Accepted: 26 March 2021 / Published online: 26 April 2021

(C) The Author(s) 2021

\begin{abstract}
Summary
Background It is generally accepted that angiogenesis is a complex and tightly regulated process characterized by the growth of blood vessels from existing vasculature. Activation of the Notch signalling pathway affects multiple aspects of vascular development. One of the components of the Notch signalling pathway, Delta-like ligand 4 (DLL4), has recently appeared as a critical regulator of tumour angiogenesis and thus as a promising therapeutic target.

Methods This review article includes available data from peer-reviewed publications associated with the role of DLL4 in cancer angiogenesis. Searches were performed in PubMed, EMBASE, Google Scholar and Web of Science using the terms "tumour angiogenesis", "DLL4", "Notch signalling" and "anti-cancer therapy".

Results The survival curves of cancer patients revealed that the patients with high DLL4 expression levels had significantly shorter survival times than the patients with low DLL4 expression. Moreover, a positive correlation was also identified between DLL4 and VEGF receptors' expression levels. It seems that inhibition of DLL4 may exert potent growth inhibitory effects on some tumours resistant to anti-VEGF therapies. A great number of blocking agents of DLL4/Notch signalling including anti-DLL4 antibodies, DNA vaccination, Notch antibodies and gamma-secretase inhibitors have been studied in preclinical tumour models.

Conclusion DLL4 seems to be a promising target in anti-cancer therapy. Nevertheless, the careful evalu-
\end{abstract}

\footnotetext{
M. Brzozowa-Zasada ( $\bowtie)$

Department of Histology and Cell Pathology in Zabrze,

Faculty of Medical Sciences in Zabrze, Medical University of Silesia, 40-055 Katowice, Poland

marlena.brzozowa@op.pl; mbrzozowa@sum.edu.pl
}

ation of adverse effects on normal physiological processes in relation to therapeutic doses of anti-DLL4 drugs will be significant for advancement of DLL4 blocking agents in clinical oncology.

Keywords Angiogenic sprouting · Canonical Notch pathway · Vascular expression - Tumour blood vessels · Antibodies

\section{Introduction}

It is generally accepted that angiogenesis is a complex and tightly regulated process characterized by the growth of blood vessels from existing vasculature. Angiogenesis is indispensable for some physiological processes such as foetal development and wound healing, whereas pathological angiogenesis is a significant feature of cancer biology. The biological functions of the tumour blood vessels and the normal functions of the blood vessels are practically identical. The process of tumour formation is also virtually identical $[1,2]$. It is formed by angiogenic sprouting and is closely related to the proliferation and migration of endothelial cells. As a result of stimulation, pericytes are generated in normally immobile blood vessels by pro-angiogenic stimuli from inflammatory and neoplastic cells. The next stage is their separation from the basement membrane. In this step, they are partially assisted by proteolysis by matrix metalloproteinases (MMPs). At the same time, the vascular endothelial growth factor (VEGF) revives the penetration of the endothelial cell sheath (functioning by relaxing tight connecting elements between endothelial cells). The result is a massive extravasation of plasma proteins that forms the backbone of the extracellular matrix. The consequence of this is that endothelial cells press against the surrounding matrix and form the lumen of the primary germinating vessel through 
proliferation, migration, deformation and dense anastomosis with each other. This process is assisted by the basal membrane and the pericytes that cover the endothelial envelope. In the final stage, they accumulate with primary blood vessels and form tumour perfusion [3-5]. Significantly pathological tumour blood vessels are deficient. They consist of a greater number of immature structures: incomplete basement membrane, reduced pericyte coverage, deficit of densely connecting elements between endothelial cells and minimal blood perfusion. Hence, the vascular system in neoplastic tissues plays an important role in twisted and deformed neovascularization of gigantic penetration [6]. Structural defects and a perfusion deficit contribute to the failure of tumour vessels to actively supply nutrients and get rid of destructive metabolic waste. Such action leads to hypoxia and acidosis in the tumour microenvironment [7]. Solid tumours try to repair quality deficits by intensifying the number of blood vessels under demanding conditions. Such connections often lead to the development of more pathological tumour angiogenesis [8].

It has been widely reported that formation of blood vessels appeared to be a key process driving tumorigenesis. Therefore, targeting tumours with angiogenesis-based therapy remains a very significant area of study. As revealed by the studies, activation of the Notch signalling pathway may affect multiple aspects of vascular development $[9,10]$. One of the components of the Notch signalling pathway, Delta-like ligand 4 (DLL4), has recently appeared as a critical regulator of tumour angiogenesis and thus as a promising therapeutic target $[11,12]$. The aim of this review was to discus and assess all relevant studies associated with the role of DLL4 in cancer angiogenesis and cancer therapy. Papers published between 2005 and March 2021 were included. Searchers were performed in PubMed, EMBASE, Google Scholar and Web of Science using the terms "tumour angiogenesis", "DLL4", "Notch signalling" and "anti-cancer therapy". Moreover, some papers were cross-checked from reference lists of included papers.

\section{Notch signalling pathway}

The Notch pathway is generally accepted as an evolutionarily conserved cell signalling mechanism participating in a great number of cellular processes, e.g., proliferation, differentiation, apoptotic cell death and stem cell maintenance [13-15]. There are four Notch receptors: Notch1, 2, 3, and 4. Each of them is synthesized as a precursor form composed of extracellular, transmembrane and intracellular domains. Within the Golgi apparatus, the precursor Notch protein is cleaved by a furin-like convertase to form two subunits. One subunit contains most of the extracellular domain and the second subunit consists of the rest of the extracellular and transmembrane domains. The Notch ligand family comprises five members:
Jagged 1/2 and Delta-like 1/3/4 (DLL1/3/4), which are also single-pass type I transmembrane proteins. The extracellular domain of the Notch receptor has been demonstrated to contain 36 EGF-like repeats [16]. Ligand binding to EGF-like repeats unfolds the negative regulatory region (NRR), permitting the next cleavage by metalloproteases of the ADAM family [11]. During the next step, the secretase complex executes an intramembrane cleavage releasing the Notch intracellular domain (NotchIC or NICD), which undergoes translocation to the nucleus. It has been reported that for activation of Notch signalling, the Mastermindlike family of proteins (MAML1/2/3) are required. MAML forms a ternary complex with CBF1-NotchIC via direct interaction with NotchIC. Then, the ternary complex composed of CBF1-NotchIC-MAML acts as a transcription activator, resulting in Notch target gene transcription. Among the primary targets, there are several genes belonging to the basic helix-loophelix (bHLH) family. Following Notch activation, at least two families of bHLH proteins are induced: the Hairy/Enhancer-of-Split (HES) family and the HairyRelated Transcription factor (HRT) family ([17]; Fig. 1).

Although a great number of Notch cellular responses occur as a result of activation of the canonical Notch pathway described above, there are other proteins that may also act as a Notch ligands and be responsible for Notch activation. In this noncanonical pathway, other transmembrane proteins are involved: Dner, F3/contactin-1 and NB-3/contactin-6. It should be pointed out that these Notch ligands bind Notch receptors with less affinity than the conventional Notch ligands, which is associated with the lack of a DSL region in their structure [18].

\section{The prognostic role of DLL4 expression in tumour vasculature}

Abundant studies in humans and mice have demonstrated that DLL4 is strongly expressed by the tumour vasculature and generally not by the tumour cells themselves. In various mouse models, high DLL4 expression was observed in the majority of tumour vessels, compared with significantly lower vascular expression in adjacent normal tissue. For example, the expression of DLL4 within the vasculature of clear cell renal cell carcinoma was upregulated almost ninefold compared to normal kidney tissue and was correlated with the level of VEGF. What is interesting is that the expression of DLL4 in endothelial cells was upregulated by VEGF. The inhibition of DLL4 was associated with inhibition of endothelial cell proliferation, migration and network formation [19]. The survival curves of clear cell renal carcinoma (CCRC) patients revealed that the patients with high DLL4 expression levels had significantly shorter survival times than the patients with low DLL4 expression. The presence of high DLL4 was clearly associated with reduced overall survival and progression-free survival 


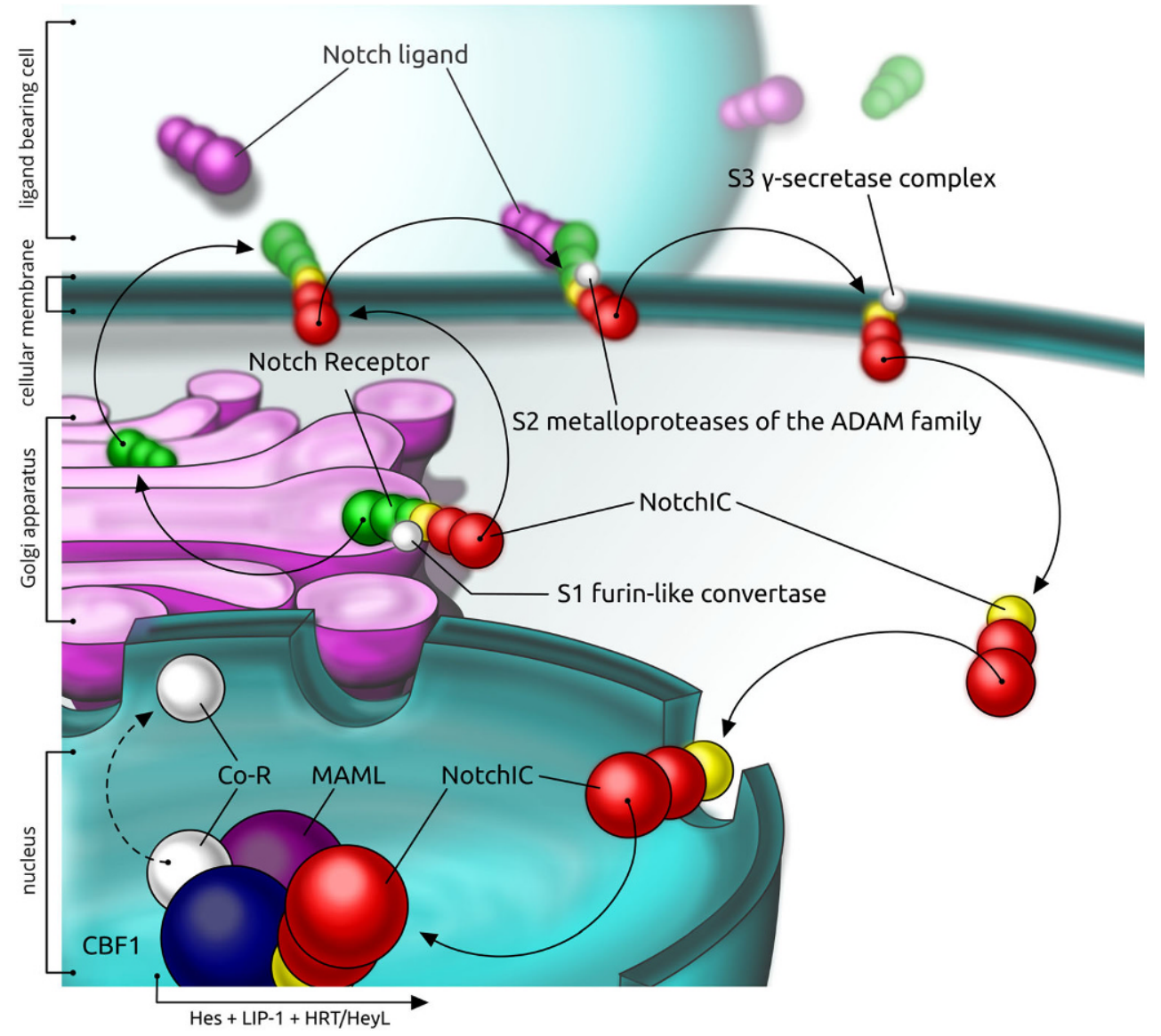

Fig. 1 Notch receptors are synthesized as immature precursors in the endoplasmic reticulum. Following proteolytic cleavage by furin-like convertase ( $\mathrm{S} 1$ cleavage) in the transGolgi, mature Notch receptors accumulate on the cell surface as heterodimers composed of the Notch extracellular domain (NECD), the transmembrane domain (NTM) and the intracellular domain (NICD), held together by non-covalent interactions. Notch signalling-induced trans-activation is triggered by contact between a membrane-associated ligand on the signal-sending cell and a Notch-transmembrane receptor on the signal-receiving cell. The interaction with the ligand predis-

times. Moreover, a positive correlation was also identified between DLL4 and vascular endothelial growth factor receptor-2 (VEGFR2) expression levels. It seems that inhibition of DLL4 may exert potent growth-inhibitory effects on CCRC tumours resistant to antiVEGF therapies [20, 21]. Wang et al. revealed that the high level of DLL4 expression has been conected with silencing UCA1 (urothelial cancer associated 1) and inhibition of metastatic ability of renal cancer cells. This factor is a novel IncRNA that acts as a potential biomarker and is involved in the development of cancers [22]. Huang et al. revealed that the levels of DLL4 continued to increase in cases of haematogenic CCRC metastases, while on the other hand, miR30a continued to decrease in cases of haematogenic CCRC metastases. It should be pointed out that miR30a expression was not equally associated with DLL4 expression and vascular consistency [23]. poses the Notch receptor to cleavage by ADAM metalloproteases (S2 cleavage), which allows subsequent cleavage by the gamma secretase (GS) complex (S3 cleavage). S3 cleavage leads to the release of active NICD from the membrane, which translocates to the nucleus and regulates the transcription of specific target genes including Hairy/Enhancer of Split (HES) family proteins, HES-related proteins (HEY), Notchregulated ankyrin-repeat protein and p21cip/waf1, cyclin D1 and 3, c-myc and HER2. CBF1 C promoter-binding factor 1, Co- $R$ Histone deacetylase co-repressor, LIP-1 lateral signaling induced phosphatase-1

The importance of DLL4 expression in lung cancer is ambiguous. Expression of DLL4 was associated with potentiated hypoxia- $1 \alpha$ (HIFl $\alpha$ ), microvessel density (MVD) and VEGF $[24,25]$. Overexpression of endothelial DLL4 in mice diagnosed with Lewis lung carcinoma (LLC) gradually reduced VEGF-R2 expression. This was associated with a reduction in the sensitivity of the vessels to the expression of VEGFR2, thus leading to a reduction in the consistency of the endothelium. The stimulation of DLL4 allowed for greater spread of chemotherapeutic drugs to the tumour site, because the tumour vasculature was significantly developed and invariant [26]. Moreover, sometimes endothelial cells expressing DLL4 (EC) help block the proliferation of the co-forming NSCLC cells by stimulating Notch1/PTEN signalling in NSCLC cells. It can be concluded from this that endothelial DLL4 led to cell weakening in lung cancer [27]. 
In the case of superficial and invasive bladder cancer, the expression of DLL4 was largely increased too. Additionally, expression of DLL4 was significantly associated with VEGF [28]. It was noted that DLL4 showed high expression in breast cancer in intratumoural endothelial cells and ductal carcinoma cells (approximately 100\%). Breast cancer with the high level of DLL4 expression in the vasculature probably progressed faster due to the high activity of endothelial DLL4 [29]. The enhanced expression of DLL4 was connected with tumour vascular endothelial cells and rarely with tumour cells in glioblastoma patients. Moreover, a significant correlation of high DLL4 expression with shorter time to progression (TTP) and OS was established [30]. Qiu et al. revealed that high DLL4 expression was positively related to PTBE [31].

\section{The complex interplay between DLL4 and VEGF}

A few years ago, the VEGF pathway began to be used in cancer therapy. In the course of research, it was discovered that blockade of the VEGF-A ligand with a monoclonal antibody may contribute to tumour development. More efforts have been made to find a suitable way to reduce the VEGF pathways. The goal was to block the VEGF-A ligand and the VEGFR2 receptor [32]. Research results demonstrated that inhibition of this pathway in tumour-bearing mice was associated with vessel clipping and reduction of angiogenic sprouting [33]. Reduced tumour angiogenesis contributes to the reduction of tumour growth in various types of cancer. These results have been substantiated in proven phase III clinical trials of anti-VEGF drugs (colon cancer, renal cell carcinoma and breast cancer). Studies have shown that DLL4 expression plays a very important role in modulating VEGF signalling. It seems then that the balance between these two pathways may play an important role as a result of the therapeutic modification of their signalling [34]. Blocking Notch signalling by inhibiting DLL4 or by reducing the Notch signalling enzyme complex (gamma secretase) damaged normal vascular organization and function. On the other hand, it stimulated the number of endothelial cells involved in germination and vessel density [35]. Third, increasing the level of Notch DLL4 ligand reduced VEGF-activated proliferation of endothelial cells and inhibited VEGFR2 expression. By attaching Notch inhibitors to this, the effect can be quite the opposite. VEGF signalling is "located above" the Notch pathway, and induction of VEGF signalling stimulates Notch signalling by enhancing expression of Notch ligands, e.g., DLL4. Increasing the Notch ligands and their binding to associated Notch receptors reduced VEGFR2 expression. It can be concluded that the Notch pathway trims and creates patterns of vascular networks [36]. It does this by locally standardizing the sensitivity of endothelial cells to global VEGF pro-angiogenic factors. On the other hand, blocking
Notch/DLL4 contributes to an increase in VEGFR2 mRNA expression. Thus, VEGF activates angiogenesis and Notch signalling helps VEGF do this. A reasonable solution would be to introduce combined DLL4 and VEGF in cancer therapy [37]. Some studies revealed that DLL4 itself contributes to tumour growth through bevacizumab, a VEGF inhibitor. The combined blocking of DLL4 and VEGF signalling was clearly associated with sensitization of the tumour to VEGF block, thereby rendering the tumour hypoxic and reducing tumour growth and angiogenesis several fold. DLL4 mediated tumour resistance to bevacizumab, which is a known VEGF inhibitor. In consequence it may lead to tumour regrowth and the generation of residual well-organized large vessels [38]. The combined suppression of DLL4 and VEGF signalling can re-sensitize tumours to VEGF inhibition, enhancing tumour hypoxia and reducing tumour angiogenesis [39]. In recent years, some bispecific monoclonal antibodies targeting both hDLL4 and hVEGF have been established and show inhibitory effects on tumour cells and the vasculature. Among them it should be mentioned about navicixizumab [40], HD-105 [41], Hb-32 [42] and ABT-165 [43].

\section{Some promising ways of targeting DLL4 during anti-cancer therapy}

A great number of blocking agents of DLL4/Notch signalling, including anti-DLL4 antibodies, DNA vaccination, soluble DLL4-Fc, Notch Fc decoys, Notch antibodies and gamma-secretase inhibitors have been studied in preclinical tumour models [36-43]. As mentioned above, one of these approaches is connected to specific targeting of DLL4 by the use of anti-DLL4 antibodies. Humanized anti-DLL4 (anti-hDLL4) IgG antibodies are commonly used in pre- or clinical studies to suppress cancer development by means of reducing CSC frequency [44] and to inhibit tumour angiogenesis by inducing the production of immature non-functional blood vessels [45]. It should be mentioned that despite its potent anti-tumour activity, anti-DLL4 antibodies demonstrate a high level of toxicity [43-45]. After an in-depth analysis of anti-hDLL4 IgG antibodies in athymic nude mice, anti-DLL4 antibodies contributed to non-linear pharmacokinetics (PK) and rapidly spread to lung and liver. With more intensive dosing (more than $10 \mathrm{mg} / \mathrm{kg}$ ), the clearance was reduced [46]. Importantly, recruitment of DLL4 in normal tissues may in some ways block VEGFR2, which abnormally activates Notch/VEGF signalling, transforms vascular homeostasis and contributes to pathological EC activation [47]. In the livers of animal models such as mice, rats and cynomolgus monkeys, the anti-DLL4 treatment contributes to pathological changes such as sinusoidal (SD) development, medico-lobular atrophy of the liver, bile duct proliferation and liver malfunction. It was also noted that vascular lesions appeared in the skin, heart and lungs 
of rats [47]. Anti-DLL4 $\mathrm{F}\left(\mathrm{ab}^{\prime}\right)_{2}$ antibodies reduce the full length of IgG, which is associated with inhibition of DLL4 toxicity. They have a short lifetime and, unlike IgG anti-hDLL4 antibodies, which have anti-cancer applications, they are eliminated from the body faster. It can be seen that overall toxicity is reduced while anti-DLL4 liver toxicity is unavoidable at the genetic level [48]. The anti-DLL4 3Nb3 nanobody is reduced to the value of $15 \mathrm{kD}$ and is characterized by higher affinity and specificity for the DLL4 antigen [49]. Nanobodies have a shorter lifetime and significantly higher clearance than antibodies. It is assumed that nanobodies reduce the toxicity associated with inhibition of DLL4, but this has never been scientifically proven. In addition to nanobodies, the GD16-PTXNP nanomedicine profiled on DLL4 was also specified. During preclinical studies, it was found that it has an anti-angiogenic effect on $\mathrm{FaDu}$ subcutaneous xenografts [50]. GD16-PTX-NP is responsible for the release and long-term effect of the anti-angiogenic model drug paclitaxel. Additionally, it is conditioned by the GD1 peptide which binds tumour endothelial DLL4 together [50].

\section{Conclusion}

1. Notch ligand DLL4 has appeared as a critical factor regulating the process of tumour angiogenesis.

2. Inhibition of DLL4 results in non-productive angiogenesis with an inhibitory effect on tumour development.

3. The careful evaluation of adverse effects on normal physiological processes in relation to therapeutic doses of anti-DLL4 drugs will be significant for advancement of DLL4 blocking agents in clinical oncology.

Conflict of interest M. Brzozowa-Zasada declares that she has no competing interests.

Open Access This article is licensed under a Creative Commons Attribution 4.0 International License, which permits use, sharing, adaptation, distribution and reproduction in any medium or format, as long as you give appropriate credit to the original author(s) and the source, provide a link to the Creative Commons licence, and indicate if changes were made. The images or other third party material in this article are included in the article's Creative Commons licence, unless indicated otherwise in a credit line to the material. If material is not included in the article's Creative Commons licence and your intended use is not permitted by statutory regulation or exceeds the permitted use, you will need to obtain permission directly from the copyright holder. To view a copy of this licence, visit http://creativecommons.org/licenses/by/4.0/.

\section{References}

1. Lugano R, Ramachandran M, Dimberg A. Tumor angiogenesis: causes, consequences, challenges and opportunities. Cell Mol Life Sci. 2020;77(9):1745-70. https://doi.org/10. 1007/s00018-019-03351-7.
2. Hida K, Maishi N, Annan DA, Hida Y. Contribution of tumor endothelial cells in cancer progression. Int J Mol Sci. 2018;19(5):1272. https://doi.org/10.3390/ijms19051272.

3. Haibe Y, Kreidieh M, El Hajj H, Khalifeh I, Mukherji D, Temraz S, et al. Resistance mechanisms to anti-angiogenic therapies in cancer. Front Oncol. 2020;27(10):221. https:// doi.org/10.3389/fonc.2020.00221.

4. Zhao Q, Lin R, Liu C, Zhao J, Si G, Song L, et al. Quantitative analysis on in vivo tumor-microvascular images from optical-resolution photoacoustic microscopy. J Biophotonics. 2019;12(6):e201800421. https://doi.org/10.1002/ jbio.201800421.

5. Giatromanolaki A, Sivridis E, Koukourakis MI. Tumour angiogenesis: vascular growth and survival. APMIS. 2004;112(7-8):431-40. https://doi.org/10.1111/j.16000463.2004.apm11207-0804.x.

6. Viallard C, Larrivée B. Tumor angiogenesis and vascular normalization: alternative therapeutic targets. Angiogenesis. 2017;20(4):409-26. https://doi.org/10.1007/s10456017-9562-9.

7. De Bock K, Cauwenberghs S, Carmeliet P. Vessel abnormalization: another hallmark of cancer? Molecular mechanisms and therapeutic implications. Curr Opin Genet Dev. 2011;21(1):73-9. https://doi.org/10.1016/j.gde.2010. 10.008.

8. Duru G, van Egmond M, Heemskerk N. A window of opportunity: targeting cancer endothelium to enhance immunotherapy. Front Immunol. 2020;11:584723. https:// doi.org/10.3389/fimmu.2020.584723.

9. Brzozowa-Zasada M, Piecuch A, Michalski M, Segiet O, Kurek J, Harabin-Słowińska M, et al. Notch and its oncogenic activity in human malignancies. Eur Surg. 2017;49(5):199-209. https://doi.org/10.1007/s10353-0170491-z.

10. Brzozowa-Zasada M, Piecuch A, Dittfeld A, Mielańczyk $€$, Michalski M, Wyrobiec G, et al. Notch signalling pathway as an oncogenic factor involved in cancer development. Contemp Oncol (Pozn). 2016;20(4):267-72. https://doi. org/10.5114/wo.2016.61845.

11. Sainson RC, Harris AL. Anti-Dll4 therapy: can we block tumour growth by increasing angiogenesis? Trends Mol Med. 2007;13(9):389-95. https://doi.org/10.1016/j.molmed. 2007.07.002.

12. Noguera-Troise I, Daly C, Papadopoulos NJ, Coetzee S, Boland P, Gale NW, et al. Blockade of Dll4 inhibits tumour growth by promoting non-productive angiogenesis. Nature. 2006;444(7122):1032-7. https://doi.org/10.1038/ nature05355.

13. Koch U, Radtke F. Notch and cancer: a double-edged sword. Cell Mol Life Sci. 2007;64(21):2746-62. https://doi.org/10. 1007/s00018-007-7164-1.

14. Brzozowa-Zasada M, Piecuch A, Segiet O, Stęplewska K, Gabriel A, Wojnicz R. The complex interplay between notch signaling and snaill transcription factor in the regulation of epithelial-mesenchymal transition. Eur Surg. 2015;47:218-25. https://doi.org/10.1007/s10353015-0339-3.

15. Brzozowa M, Mielańczyk L, Michalski M, Malinowski L, Kowalczyk-Ziomek G, Helewski K, et al. Role of notch signalingpathwayingastric cancerpathogenesis. Contemp Oncol (Pozn). 2013;17(1):1-5. https:// doi.org/10.5114/wo. 2013.33765.

16. BorggrefeT, LiefkeR. Fine-tuning of theintracellularcanonical notch signaling pathway. Cell Cycle. 2012;11(2):264-76. https://doi.org/10.4161/cc.11.2.18995. 
17. Leong KG, Karsan A. Recent insights into the role of notch signaling in tumorigenesis. Blood. 2006;107(6):2223-33. https://doi.org/10.1182/blood-2005-08-3329.

18. Hossain F, Majumder S, Ucar DA, Rodriguez PC, Golde TE, Minter LM, et al. Notch signaling in myeloid cells as a regulator of tumor immune responses. Front Immunol. 2018;9:1288. https://doi.org/10.3389/fimmu.2018.01288.

19. Patel NS, Li JL, Generali D, Poulsom R, Cranston DW, Harris AL. Up-regulation of delta-like 4 ligand in human tumor vasculature and the role of basal expression in endothelial cell function. Cancer Res. 2005;65(19):8690-7. https://doi.org/10.1158/0008-5472.CAN-05-1208.

20. Wang W, Yu Y, Wang Y, Li X, Bao J, Wu G, et al. Delta-like ligand 4: a predictor of poor prognosis in clear cell renal cell carcinoma. OncolLett. 2014;8(6):2627-33. https://doi.org/ $10.3892 / \mathrm{ol} .2014 .2554$

21. Hu GH, Liu H, Lai P, Guo ZF, Xu L, Yao XD, et al. Delta-like ligand 4 (Dll4) predicts the prognosis of clear cell renal cell carcinoma, and anti-Dll4 suppresses tumor growth in vivo. Int JClin Exp Pathol. 2014;7(5):2143-52.

22. Wang W, Hu W, Wang Y, An Y, Song L, Shang P, et al. Long non-coding RNA UCA1 promotes malignant phenotypes of renal cancer cells by modulating the miR-182-5p/DLL4 axis as a ceRNA. Mol Cancer. 2020;19(1):18. https://doi.org/10. 1186/s12943-020-1132-X.

23. Huang QB, MaX, Zhang X, Liu SW, Ai Q, Shi TP, et al. Downregulated miR-30a in clear cell renal cell carcinoma correlated with tumor hematogenous metastasis by targeting angiogenesis-specific DLL4. PLoS One. 2013;8(6):e67294. https://doi.org/10.1371/journal.pone.0067294.

24. Yu S, Sun J, Zhang J, Xu X, Li H, Shan B, et al. Aberrant expression and association of VEGF and Dll4/Notch pathway molecules under hypoxia in patients with lung cancer. Histol Histopathol. 2013;28(2):277-84. https://doi.org/10. 14670/HH-28.277.

25. Pedrosa AR, Trindade A, Fernandes AC, Carvalho C, Gigante J, Tavares AT, et al. Endothelial jaggedl antagonizes Dll4 regulation of endothelial branching and promotes vascular maturation downstream of Dll4/notch1. Arterioscler Thromb Vasc Biol. 2015;35(5):1134-46. https://doi.org/10. 1161/ATVBAHA.114.304741.

26. Trindade A, Djokovic D, Gigante J, Mendonça L, Duarte A. Endothelial Dll4 overexpression reduces vascular response and inhibits tumor growth and metastasization in vivo. BMC Cancer. 2017;17(1):189. https://doi.org/10.1186/ s12885-017-3171-2.

27. Ding XY, Ding J, Wu K, Wen W, Liu C, Yan HX, et al. Cross-talk between endothelial cells and tumor via deltalike ligand 4/Notch/PTEN signaling inhibits lung cancer growth. Oncogene. 2012;31(23):2899-906. https://doi.org/ 10.1038/onc. 2011.467.

28. Patel NS, Dobbie MS, Rochester M, Steers G, Poulsom R, Le Monnier K, et al. Up-regulation of endothelial delta-like 4 expression correlates with vessel maturation in bladder cancer. Clin Cancer Res. 2006;12(16):4836-44. https:// doi. org/10.1158/1078-0432.CCR-06-0285.

29. Jubb AM, Soilleux EJ, Turley H, Steers G, Parker A, Low I, et al. Expression of vascular notch ligand delta-like 4 and inflammatory markers in breast cancer. Am J Pathol. 2010;176(4):2019-28. https://doi.org/10.2353/ ajpath.2010.090908.

30. Qiu XX, Chen L, Wang CH, Lin ZX, Zhou CF, Liu SY, et al. High delta-like ligand 4 (DLL4) is correlated with peritumoral brain edema and predicts poor prognosis in primary glioblastoma. Medicine. 2014;93(8):e57. https:// doi.org/10.1097/MD.0000000000000057.
31. Qiu XX, Wang CH, Lin ZX, You N, Wang XF, Chen YP, et al. Correlation of high delta-like ligand 4 expression with peritumoral brain edema and its prediction of poor prognosis in patients with primary high-grade gliomas. J Neurosurg. 2015;123(6):1578-85. https://doi.org/10. 3171/2014.12.JNS14768.

32. Bertolini F, Marighetti P, Martin-Padura I, Mancuso P, HuLowe DD, Shaked Y, et al. Anti-VEGF and beyond: shaping a new generation of anti-angiogenic therapies for cancer. Drug Discov Today. 2011;16(23-24):1052-60. https://doi. org/10.1016/j.drudis.2011.08.007.

33. Jaiprasart P, Dogra S, Neelakantan D, Devapatla B, Woo S. Identification of signature genes associated with therapeutic resistance to anti-VEGF therapy. Oncotarget. 2020;11(1):99-114. https://doi.org/10.18632/oncotarget. 27307.

34. Thurston G, Kitajewski J. VEGF and delta-notch: interacting signalling pathways in tumour angiogenesis. $\mathrm{Br} \mathrm{J}$ Cancer. 2008;99(8):1204-9. https://doi.org/10.1038/sj.bjc. 6604484.

35. Otani Y, Yoo JY, Chao S, Liu J, Jaime-Ramirez AC, Lee TJ, et al. Oncolytic HSV-infected glioma cells activate NOTCH in adjacent tumor cells sensitizing tumors to gamma secretase inhibition. Clin Cancer Res. 2020;26(10):2381-92. https:// doi.org/10.1158/1078-0432.CCR-19-3420.

36. Zhang J, Ye J, Ma D, Liu N, Wu H, Yu S, et al. Crosstalk between leukemic and endothelial cells promotes angiogenesis by VEGF activation of the Notch/Dll4 pathway. Carcinogenesis. 2013;34(3):667-77. https://doi.org/10. $1093 /$ carcin/bgs386.

37. Kim DH, Lee S, Kang HG, Park HW, Lee HW, Kim D, et al. Synergistic antitumor activity of a DLL4/VEGF bispecific therapeutic antibody in combination with irinotecan in gastric cancer. BMB Rep. 2020;53(10):533-8. https://doi. org/10.5483/BMBRep.2020.53.10.103.

38. Negri F, Bozzetti C, Pedrazzi G, Azzoni C, Bottarelli L, Squadrilli A, et al. High levels of notch intracellular cleaved domain are associated with stemness and reduced bevacizumab efficacy in patients with advanced colon cancer. Oncol Rep. 2019;42(6):2750-8. https://doi.org/10.3892/or. 2019.7349.

39. Li JL, Sainson RC, Oon CE, Turley H, Leek R, Sheldon H, et al. DLL4-Notch signaling mediates tumor resistance to antiVEGF therapy in vivo. Cancer Res. 2011;71(18):6073-83. https://doi.org/10.1158/0008-5472.CAN-11-1704.

40. Jimeno A, Moore KN, Gordon M, Chugh R, Diamond JR, Aljumaily R, et al. A first-in-human phase la study of the bispecific anti-DLL4/anti-VEGF antibody navicixizumab (OMP-305B83) in patients with previously treated solid tumors. Invest New. Drugs. 2019;37(3):461-72. https:// doi. org/10.1007/s10637-018-0665-y.

41. Lee D, Kim D, Choi YB, Kang K, Sung ES, Ahn JH, et al. Simultaneous blockade of VEGF and Dll4 by HD105, a bispecific antibody, inhibits tumor progression and angiogenesis. MAbs. 2016;8(5):892-904. https://doi.org/10.1080/ 19420862.2016.1171432.

42. Zhou R, Wang S, Wen $\mathrm{H}$, Wang M, Wu M. The bispecific antibody HB-32, blockade of both VEGF and DLL4 shows potent anti-angiogenic activity in vitro and anti-tumor activity in breast cancer xenograft models. Exp Cell Res. 2019;380(2):141-8. https://doi.org/10.1016/j.yexcr.2019. 04.025 .

43. Li Y, Hickson JA, Ambrosi DJ, Haasch DL, Foster-Duke KD, Eaton LJ, et al. ABT-165, a dual variable domain immunoglobulin (DVD-Ig) targeting DLL4 and VEGF, demonstrates superior efficacy and favorable safety profiles in 
preclinical models. Mol Cancer Ther. 2018;17(5):1039-50. https://doi.org/10.1158/1535-7163.MCT-17-0800.

44. Fischer M, Yen WC, Kapoun AM, Wang M, O'Young G, Lewicki J, et al. Anti-DLL4 inhibits growth and reduces tumor-initiating cell frequency in colorectal tumors with oncogenic KRAS mutations. Cancer Res. 2011;71(5):1520-5. https://doi.org/10.1158/0008-5472. CAN-10-2817.

45. Wang S, Wen H, Fei W, Zhao Y, Feng Y, Kuang L, et al. Two engineered site-specific antibody-drug conjugates, HLmD4 and HLvM4, have potent therapeutic activity in two DLL4-positive tumour xenograft models. Am J Cancer Res. 2020;10(8):2387-408.

46. Kamath AV, Yip V, Gupta P, Boswell CA, Bumbaca D, Haughney P, et al. Dose dependent pharmacokinetics, tissue distribution, and anti-tumor efficacy of a humanized monoclonal antibody against DLL4 in mice. MAbs. 2014;6(6):1631-7. https://doi.org/10.4161/mabs.36107.

47. Djokovic D, Trindade A, Gigante J, Pinho M, Harris AL, Duarte A. Incomplete Dll4/ notch signaling inhibition promotes functional angiogenesis supporting the growth of skin papillomas. BMC Cancer. 2015;28(15):608. https:// doi.org/10.1186/s12885-015-1605-2.

48. Jarzabek MA, Proctor WR, Vogt J, Desai R, Dicker P, Cain G, et al. Interrogation of transcriptomic changes associated with drug-induced hepatic sinusoidal dilatation in colorectal cancer. PLoS ONE. 2018;13(6):e198099.https://doi.org/10. 1371/journal.pone.0198099.

49. Baharlou R, Tajik N, Behdani M, Shokrgozar MA, Tavana V, Kazemi-Lomedasht F, et al. An antibody fragment against human delta-likeligand-4 for inhibition of cell proliferation and neovascularization. Immunopharmacol Immunotoxicol. 2018;40(5):368-74.https://doi.org/10.1080/08923973. 2018.1505907.

50. Liu YR, Guan YY, Luan X, Lu Q, Wang C, Liu HJ, et al. Deltalike ligand 4-targeted nanomedicine for antiangiogenic cancer therapy. Biomaterials. 2015;42:161-71. https://doi. org/10.1016/j.biomaterials.2014.11.039.

Publisher's Note Springer Nature remains neutral with regard to jurisdictional claims in published maps and institutional affiliations. 